\title{
Staphylococcus aureus pyomyositis and septic lung emboli
}

\author{
Deepak Chaudhary MD, Tanushi Aggarwal MBBS, Ashok Kumar Pannu MD
}

Cite as: CMAJ 2022 January 31;194:E126. doi: 10.1503/cmaj.210782

A 14-year-old boy of low socioeconomic status presented to our emergency department with a 3-4-day history of high-grade fever, left thigh pain and difficulty breathing. He had been previously well, had no history of trauma and did not use illicit drugs. On examination, he appeared thin and malnourished (body mass index 17). His left thigh was swollen, warm and tender, and motion was restricted because of pain. Laboratory investigations showed a hemoglobin level of 85.0 (normal 120.0-140.0) g/L, leukocyte count of 18.6 (normal 4.0-11.0) $\times 10^{9} \mathrm{~L}$ and albumin level of 18.6 (normal 34.0-48.0) g/L. We saw multiple hyperintense collections in the intermuscular planes in his left thigh on $T_{2}$-weighted magnetic resonance imaging (Figure $1 \mathrm{~A}$ ). Thoracic computed tomography scans showed peripheral lung nodules of varying sizes; some had a feeding vessel, suggesting hematogenous spread of infection (Figure 1B).

We aspirated an intramuscular collection and obtained pus, but Gram staining and culture were negative. Methicillin-sensitive Staphylococcus aureus grew from his blood culture. Transthoracic echocardiograms did not show evidence of endocarditis. An HIV test was negative, and blood glucose levels were normal.

We made a diagnosis of primary pyomyositis with septic emboli to the lung. We treated the patient with intravenous cloxacillin for 3 weeks, followed by oral cloxacillin for 1 week. He improved clinically and his follow-up blood cultures were sterile.

Primary pyomyositis is an infection of skeletal muscle that results in abscess formation; the proximal muscles of the limbs are most commonly involved. ${ }^{1,2}$ The condition has largely been described in tropical and subtropical countries, but it can occur in temperate climates; 7 cases were recently described in northern Ontario. ${ }^{1-3}$ The disease typically occurs in patients who are immunocompromised or malnourished. Antecedent trauma is documented in about half of patients. Magnetic resonance imaging is more sensitive than ultrasonography to determine the extent of the infection. About $80 \%-90 \%$ of infections are caused by S. aureus. ${ }^{1,2}$ Bacteremia occurs in $10 \%-20 \%$ of patients and may result in seeding of infection, most commonly to the lungs. Treatment is with 3-4 weeks of antibiotics. Large abscesses may need to be drained.

\section{References}

1. Idelevich EA, Kreis C, Löffler B, et al. Staphylococcus aureus-associated musculoskeletal infections. Curr Top Microbiol Immunol 2017;409:229-61.

2. Gubbay AJ, Isaacs D. Pyomyositis in children. Pediatr Infect Dis J 2000;19:1009 12, quiz 1013.

3. Loewen K, Kirlew M, Benvenuto PS, et al. Northern tropics? Seven cases of pyomyositis in northwestern Ontario. J Assoc Med Microbiol Infect Dis Can 2016;1:1-7. doi: 10.3138/jammi.1.3.01.

\section{Competing interests: None declared.}

This article has been peer reviewed.

The authors have obtained patient consent.

Affiliation: Department of Internal Medicine, Postgraduate Institute of Medical Education and Research (PGIMER), Chandigarh, India

Content licence: This is an Open Access article distributed in accordance with the terms of the Creative Commons Attribution (CC BY-NCND 4.0) licence, which permits use, distribution and reproduction in any medium, provided that the original publication is properly cited, the use is noncommercial (i.e., research or educational use), and no modifications or adaptations are made. See: https://creativecommons.org/ licenses/by-nc-nd/4.0/

Correspondence to: Ashok Kumar Pannu, gawaribacchi@gmail.com 